\title{
Aspectos de Ortega y Gasset en la formación de ciudadanos
}

\author{
Aspects of Ortega y Gasset in the formation of \\ citizens \\ Miguel RUMAYOR \\ Universidad Panamericana, Guadalajara, México
}

Recibido: Febrero 2015

Evaluado: Marzo 2015

Aceptado: Mayo 2015

\section{Resumen}

José Ortega y Gasset no puede ser clasificado como teórico o filósofo de la educación, aunque sus obras poseen importantes reflexiones en ese ámbito del conocimiento. Concretamente en este artículo se pone de manifiesto el valor de la filosofía racio-vitalista y la formación de ciudadanos en la perspectiva personal, lo cual contribuirá a la construcción de la sociedad y a la vida democrática. Además, a la luz del liberalismo político de este autor en el artículo se analizan, ente otras, sus importantes ideas sobre la libertad, el patriotismo, la ciudadanía, la elegancia y la tolerancia, como grandes aportaciones conceptuales a la tarea educativa. Básicamente todo el pensamiento de Ortega se concretará en formar profundamente la intimidad personal de los ciudadanos. Este elemento se muestra como el centro y el objetivo de la formación y en torno a él giran los aspectos sociales y personales de la educación de ciudadanos analizados en este escrito.

Palabras clave: educación de ciudadanos, Ortega y Gasset, educación moral, educación de la intimidad, educación para la democracia.

\begin{abstract}
José Ortega y Gasset cannot be classified as theorist or philosopher of education, although his works possess important reflections in this field of knowledge. Specifically, this article highlights the value of the raciovitalist philosophy and the formation of citizens in the personal perspective, which will contribute to the construction of society and democratic life. In addition to this, in light of the political liberalism of this author, this article analyzes, among others, his important ideas about freedom, patriotism, citizenship, elegance and tolerance, as great conceptual contributions to the educational task. Basically all thought of Ortega will be focused on deeply shaping the personal intimacy of citizens. This element is displayed as the center and the goal of education, and all social and personal aspects of the formation of citizens spinning exposed in the writing spinning around this idea, are analyzed in this paper.
\end{abstract}

Keywords: education of citizens, Ortega y Gasset, moral education, education of intimacy, education for democracy. 


\section{Ortega y la educación}

José Ortega y Gasset se encuentra entre los autores más citados internacionalmente en la reciente cultura hispana. Así lo demuestran, entre otras cosas, las múltiples ediciones y traducciones hechas a sus libros Meditaciones del Quijote (1914), El Tema de Nuestro tiempo (1923), Ideas y Creencias (1940), o su obra tal vez más famosa: La Rebelión de las Masas (1930). Es famoso su ensayismo político, difundido personalmente como agudo conferenciante y también por la participación activa en la política española antes y durante la Segunda República en 1931. Han recibido amplia divulgación sus ideas acerca de la sociedad, del arte, del amor, de España como nación, sobre Hispanoamérica. Se valora la profunda originalidad de su filosofía, junto con muchos otros temas que abordó con inteligencia, erudición y a veces con fina ironía. Sin embargo, aunque habitualmente se nombran tres etapas en su pensamiento: objetivismo, perspectivismo y raciovitalismo, que nos hablan de cierta linealidad en su obra, cuando se trata exponer el pensamiento orteguiano, desde los orígenes y porqués de su modo de pensar hasta las aplicaciones concretas del mismo, el asunto se torna dificultoso y más aún en lo relacionado a sus reflexiones educativas.

Y es que Ortega no fue un filósofo al uso, ni tampoco un teórico como tal de la educación, comprometido en todo momento con una exposición ordenada de una cierta realidad educativa. Se trata, más bien, de un pensador que va y viene siempre encaramado a lomos de la circunstancia de su propia vida (Ruíz Fernández, 2009), como a él metafóricamente le gustaba decir, que a veces también pretende aclarar -acto de cortesía del filósofo lo denomina- elementos claves para el mundo educativo, arrojando luces sobre algunos temas, intuiciones geniales y, en ciertos momentos, falta de claridad y contradicciones de difícil entendimiento. Así, el propósito de este escrito consistirá en destacar algunos aspectos valiosos del pensamiento de este autor, los cuales sirvan para una fundamentación más exitosa del tema de la formación de ciudadanos. Labor que de manera recurrente ha sido tan debatida en nuestro país, fundamentándose filosóficamente en autores tan variados y distintos como John Dewey, Hannah Arendt, John Rawls, Paulo Freire, Jünger Habermas, o los españoles Adela Cortina e Ignacio Ellacuría, entre algunos otros, y sus apreciaciones sobre la participación en el poder, la sociedad, el pragmatismo, la ética social, el liberalismo, el contractualismo o la ética dialógica, por poner algunos ejemplos. De todos ellos se han derivado programas e ideas educativas que se han tratado de aplicar con diverso acierto dentro y fuera de España, y el debate sigue abierto. Por ello este tema estará siempre necesitado de una mayor nitidez conceptual y, de forma particular, para su aplicación exitosa al entorno hispano. De ahí la importancia de acudir a José Ortega y Gasset, ya que nos señala aspectos formativos sencillos y poco conocidos, aunque no por ello menos profundos, aplicables a la formación de ciudadanos y al necesario fortalecimiento de la educación democrática de nuestros días.

\section{Perspectivismo y formación política}

Se puede afirmar que la filosofía orteguiana huye de dos males. Por una parte el racionalismo tradicionalista y su visión estática, dogmática e impersonal de la realidad 
social, que trata de fijar unos patrones universales e inflexibles frente al conocimiento de las cosas y los cambios en la vida social. Por otra, el relativismo del progresismo, el cual afirma que la realidad se encuentra en permanente cambio por lo que no puede ser conocida realmente, reduciendo por ello la vida en común a lo que Ortega llama pragmatas, o lo que es igual, apreciar lo social desde una óptica poco profunda, al reducir las relaciones entre personas a "un sistema común de utilidades" (Bárcena, 1991, p. 62).

Ortega rechaza asumir que no existe un ethos universal estructurador válido para todas las sociedades. Tal ausencia supondría limitar a la persona a vagar a tientas de un lugar a otro por el mundo de las propias consideraciones subjetivas. Así, el tratamiento que hace Ortega de la valoración de la perspectiva de cada individuo a la sociedad y su aportación a la educación es interesante. Sigue la idea que posteriormente y en otra tradición tematizarán Habermas y Apel con su ética dialógica: el punto de vista de cada ciudadano, de cada educando, sobre los temas relacionados con la convivencia nunca puede ser único, porque entonces sería dogmático y dictatorial, aunque Ortega entiende que tampoco puede ser abstracto y meramente individual, ya que esto anularía elementos tan necesarios para la vida social como la existencia de la verdad, el bien y la belleza.

El filósofo al hablar del factor de la perspectiva como elemento fundamental para ser educado en las sociedades democráticas, individualiza en cada ciudadano el sentido del desarrollo de la inteligencia personal frente a la posible promoción del llamado "inconsciente colectivo" de Emile Durkheim. Ensalza la formación individual de la "conciencia política", ya que "hay ciertas ideas a las cuales sentimos indisociablemente adscrito el eje moral de nuestra persona" (Ortega, 2008f, p. 727). En relación a ello se encuentra la esencial incertidumbre de la inteligencia de cada hombre frente a lo real, que camina junto a la inevitable problematicidad de encontrar lo verdadero en el desarrollo del "poder de lo social" (Ortega, 2008h, p.102) que cada ciudadano posee.

Ortega responsabiliza a cada persona sobre su punto de vista frente a los otros y lo considera, a su vez, un elemento necesariamente compartible con el resto de ciudadanos, ya que la inteligencia no puede servir a ningún interés particular bajo pena de anularse (Ortega, 2007b, p. 184). Pero la educación en la existencia de un punto de vista personal comprometido y sólido de acceso a lo real, tan necesario en la vida democrática, solamente puede ser cabal si aquello que cada uno piensa trata de dirigirse y fundamentarse en lo que la persona considera en el fondo de su conciencia. Es el llamado por Ortega "fondo insobornable" de cada hombre. Espacio íntimo donde cada hombre busca en lo real estructuras invariantes y permanentes que fundamenten el propio punto de vista. Cuando esto se lleva a cabo en la sociedad el hombre no sólo alcanza la autenticidad, que según el pensador le hace coincidir consigo mismo (Bárcena, 1983, p. 313), sino que al mismo tiempo le convierte en verdaderamente ejemplar para el resto.

Para resaltar la importancia y actualidad de Ortega en relación al tema de la formación política hay que añadir a lo dicho que la visión en su propio tiempo de España, y de la sociedad en general, es regeneracionista, ya que desde muy joven existe en él un profundo deseo de modernización ideológica y técnica de la sociedad en 
su conjunto. Tal perspectiva está ligada a una idea de la realidad española como nación y a una concepción particular sobre la patria. Su reflexión sobre España no es impersonalmente social, ni grandilocuente, como la que se deriva de los modelos de estado hegelianos. Tampoco Ortega defiende un liberalismo individualista, irresponsable y omnicomprensivo, desarraigado de las preocupaciones cercanas del llamado por Husserl "mundo de la vida". Por el contrario su noción de patria se relacionada con su filosofía vitalista, integrada a sus conceptos sobre el liberalismo y el valor de la intimidad personal de cada ciudadano. Esta nace o debe hacerlo en el corazón y en la vida concreta de cada ciudadano. En relación con esta visión íntima y cercana, mantiene que su construcción consiste en una tarea diaria: "no es un párrafo retórico sino aquello que por la mañana pensamos que hemos de hacer durante el día" (Ortega, 2007a, p. 559) o como también afirma en otro momento: "la única realidad es la nación, nuestra nación; lo que hoy constituye nuestros quehaceres diarios" (Ortega, 2008d, p. 87). La patria no es sólo lo heredado y lo que hay que transmitir, como se puede entender a veces en un esquema de rígido tradicionalismo, sino al igual que ocurre en John Dewey también consiste en lo experiencial y venidero, lo que se puede construir y hacia lo que hay que tender esperanzadamente (Jover y Thoilliez, 2011, p. 253-267). De ahí nace el interés y alcance de su pensamiento en la formación de los ciudadanos del siglo XXI, ya que su idea de patriotismo, como sucede en McIntyre (1984, p. 16) tiene que ver con el sentido de la historia de nuestras vidas, que nos lleva a vivir una moral comprometida: "Patria en este sentido es precisamente el conjunto de virtudes que faltó y falta a nuestra patria histórica, lo que hemos sido y tenemos que ser so pena de sentirnos borrados del mapa" (Ortega, 2005a, p. 88).

Dado lo señalado hasta aquí Ortega aprecia que la función central de la política es la educación (2008g, p. 151), para que, como ha ocurrido tantas veces, no se produzca esa "selección a la inversa, que ha abandonado los intereses públicos a las manos más indignas" (Ortega, 2007e, p. 328). Y también, dándole la vuelta a la idea anterior, se puede afirmar que en Ortega la tarea fundamental de la educación será la política, la cual consistirá en la capacitación de ciudadanos para que puedan trasformar virtuosamente las sociedades (Ortega, 2005a, p. 97).

\section{La libertad y el liberalismo educativo de Ortega}

Aunque en el pensador se observa en 1910 una clara influencia socialista y neokantismo, más particularmente el influjo de las de ideas de la pedagogía social exclusivista de Natorp expuesta en Filosofía y Pedagogía (1909) y los planteamientos de Hermann Cohen recogidos en su Sistema de Filosofía (1902-1906), que hablan del inevitable condicionamiento social que tiene el hombre, no obstante en Ortega la forma de ver la política y la sociedad en el conjunto de su obra puede clasificarse como liberal. Políticamente, con influencia del pragmatismo anglosajón, en Ortega destaca un liberalismo lleno de vitalidad, en permanente diálogo con el mundo de la vida y unido a una ingente cultura hispana. Por ello sus reflexiones se orientan no sólo a la resolución de problemas de índole práctico, sino a difundir un modo particular de vivir y una serie de propuestas para la educación de las sociedades venideras. Una pedagogía 
política, no sólo en el sentido ideológico, sino también en el trasfondo moral del término (Ortega, 2008a, p. 150).

Aprecia Ortega que la vida humana es imprevisible. Vivimos como si repentinamente hubiéramos despertado en el escenario del teatro de la propia existencia: incertidumbre radical que nos hace ser constitutiva y "forzosamente" libres (Ortega, 2007c). La libertad es una fuerza que impele al ser humano a la realización de un proyecto vital y este no es otro sino su propia circunstancia personal a la que se siente vocacionalmente llamado. El hombre es y debe cincelar su libertad activa y conscientemente y de ahí nace su íntimo deseo de ser verdadero. Por eso entiende el liberalismo más allá de los programas de partido, como una ideología política dinámica, en la cual, por la propia fuerza extensiva que posee la libertad personal tendrá que permear todas las esferas de la sociedad y contribuir a la aparición de una ciudadanía comprometida, educada y culta (Ortega, 2007e, p. 330). Como consecuencia de tal inercia, de modo natural, a la larga la sociedad será dirigida por los más capacitados.

El liberalismo le lleva también a pensar en que una "inmensa minoría", utilizando la célebre frase de Juan Ramón Jiménez, que ha progresado por sus méritos, su prestigio y trabajo, será capaz de contrarrestar la frecuencia con que la que la masa necia y amorfa produce individuos planos, chatos de espíritu, sometidos impersonalmente a las vigencias sociales y con escaso ímpetu reformador. La política liberal, como la entiende Ortega, es pues un instrumento de vigorización y educación de la vida social, que consiste antes que en un instrumento político en la forma misma de la virtud civil (Cerezo Galán, 2005, p. 632). Se cimienta en un deber insoslayable y a menudo incómodo: "anticipar ideales y educar según ellos los corazones, constituye la misión impersonal, que sin ensoberbecer, obliga, impuesta por el Demiurgo que ordena la Historia a los pensadores de cada pueblo. Por eso no queremos reformar costumbres sino cultivar ideas" (Ortega, 2008g, p. 152).

Siguiendo esta idea liberal, es normal que cuando el pensador hable de los partidos políticos liberales, de su peculiar vocación revulsiva entre los ciudadanos, los considere como elementos de activación social. Estarán orientados a provocar una dinámica de preocupación por los sucesos de la sociedad y la intervención ciudadana, sin que esto suponga nunca que se vuelvan contra el sistema constitucional o pretendan desmantelarlo: "los partidos liberales en la historia universal, son partidos fronterizos de la revolución, no son nada, tomando la palabra revolución en el sentido de variación constitucional de un estado" (Ortega, 2008g, p. 149).

El pensamiento liberal orteguiano sobre el liderazgo minoritario, con claras repercusiones sociales, contrasta con lo que hoy vemos en las modernas democracias occidentales, donde penosamente ha proliferado la idea de que la intervención, la educación y la gestión de la vida pública, es una responsabilidad que pertenece algunos pocos, los políticos, y no a la sociedad en su conjunto. Hay que añadir que tales ciudadanos dedicados a los asuntos públicos muchas veces no se hallan entre los mejores, como se explica en La rebelión de las masas: se encuentran a la deriva bajo la superficie de una igualdad no deseable (Morón Arroyo, 2005, p. 684). Los llamados 
"hombres de partido", aprecia Ortega, no son siempre, ni mucho menos, los más idóneos para guiar los destinos de la nación.

Esta carencia de liberalismo como la entiende el filósofo se une a la práctica ausencia de sociedad civil dentro del mundo Hispano. Exceptuando algunas manifestaciones públicas populares ante flagrantes injusticias políticas, empresariales, o gubernamentales, los ciudadanos de nuestras sociedades, fuera de la mera emisión de un voto, no están educados para participar en la vida civil. De ahí que se comprenda la fuerza y la actualidad con la que resuenan estas palabras de Ortega: "la intervención vigorosa y consciente en la política nacional es un deber de todos, no un derecho que quede adscrito a los ciudadanos que no sirven para otra cosa, que no colaboran en otras formas al aumento moral y material de España, a los llamados «políticos»" (2008b, p. 738).

\section{Alcanzar una ciudadanía bien formada}

En la actual sociedad de la información se produce la paradoja que las personas nunca han tenido acceso tan rápido y a tanta cantidad de datos y, sin embargo, nunca socialmente ha existido con tanta nitidez la sensación en muchos de navegar aturdidos frente a la abundancia de conocimientos completamente inútiles para el desarrollo de la propia felicidad personal. Frente a esto podemos decir con Ortega que una sociedad idealmente educada en política tiene una noción clara y determinada sobre qué hace y qué sucede en cada momento y, como consecuencia de esto, sobre lo que puede ser más adecuado para sí misma. Tal ciudadanía sería conocedora de las vigencias históricas y momentáneas que determinan cada época, las cuales son, entre otras, aquellas realidades con las que contamos habitualmente y sobre las que a veces no hemos pensado suficiente, porque se hallan de modo latente en nuestra conciencia y pensamiento (Ortega, 2006c, p. 664).

De ahí lo importante que es para Ortega enseñar a los ciudadanos a captar personalmente el espíritu de los tiempos, porque, según piensa, el secreto de toda verdadera política al servicio de la sociedad consiste simplemente en declarar lo que es (2008f, p. 711) donde por lo que es entiende aquella realidad que subyace en cada cosa y que viene a constituir el sentido de cada época, en cada instante, y que conforma la opinión verdadera, íntima y latente, de la sociedad.

Por ello, la llamada por Ortega "normalidad del hombre normal" (2006d, p. 346) consiste en que cada educando posea una combinación equilibrada entre impulsividad e imaginación, vida y espíritu. De ahí también que entre las virtudes que ha de tener todo individuo políticamente educado, según Ortega, destaquen la fuerza vital, la intelección, la impetuosidad y la agudeza (2005d, p. 219).

En relación con lo dicho y por otra parte aparecen delineados con nitidez los rasgos esenciales del patriotismo formativo que propone Ortega. Magnánimo y ajeno al nacionalismo excluyente, consiste en la promoción de la excelencia personal y la elevación de la altura de miras de los educandos hacia el servicio y el proyecto social y político de cada tiempo y sociedad. Así, afirma en relación a su país: "es preciso ir 
educando a España para la óptica de la magnanimidad, ya que es un pueblo ahogado por el exceso de virtudes pusilánimes" (Ortega, 2005d, p. 202), y completando esto: "mi patriotismo no me deja aceptar sino una España mejor, una España ejemplar de cabezas claras y voluntades nobles" (Ortega, 2007, p. 843).

De tal suerte que la vida política para Ortega está relacionada con sus nociones éticas, antropológicas, sociales. El pensador madrileño nos habla de desarrollar en la ciudadanía el llamado "saber social". Este es un tipo de conocimiento que va más allá de lo estructural o lo científico y que sólo se adquiere íntimamente por el conocimiento profundo de lo que verdaderamente es el ser humano en su realidad y circunstancia concreta. En resumidas cuentas, consiste en formar a la ciudadanía para que pueda ver más allá de un ideologismo superficial, común ahora como entonces, en tópicos y opiniones huecas, "muertas y sin dinamismo" (Ortega, 2008f, p. 711), que redunda en el mundo de la política produciendo, entre otras cosas, superficialidad en la toma de decisiones. Hay que ir, por el contrario, hasta el sustrato íntimo de lo ideológico y romper esa: "piel de paquidermo humano, dura y sin poros, que impide la transmisión al interior de heridas desconcertantes" (Ortega, 2005a, p. 214). Se trata por ello de interpretar de una manera novedosa la idea de Nietzsche de "vivir en el peligro". Desde el punto de vista educativo conseguir que los ciudadanos afronten la incertidumbre que produce la posibilidad del cambio, y cada uno a su velocidad y modo, lleguen sorteando los vaivenes de la vida a los sustratos de las ideas, ya que los "ingredientes invisibles, recónditos, son, a veces, vivencias de un pueblo formadas durante milenios. Este fondo «latente» de las ideas que las sostiene, llena y nutre" (Ortega, 2012, p. 20).

Por ello, y en relación a la vida pública, cuando Ortega habla de los partidos políticos les otorga una labor educativa para la sociedad y sugiere un aspecto poco común a la realidad política de nuestros días: "los partidos en cuanto entidades parlamentarias no tienen otro papel que recoger el contenido espiritual de aspectos populares" (Ortega, 2008g, 150). Es decir, anhela que los grupos políticos no solo hagan propuestas y ofrezcan soluciones a las cuestiones más acuciantes del presente, sino que también reflejen en sus idearios los elementos fundamentales que atesoran la vida de los pueblos y que estén sabiamente conectados a la altura intelectual de la sociedad de cada época, ya que cada pueblo "tiene su alma típica, es decir, una retícula con unas mallas de amplitud y perfil definidos que le prestan rigorosa afinidad con ciertas verdades e incorregible ineptitud para llegar a ciertas otras" (Ortega, 2005c, p. $613)$.

Ortega defiende así la necesidad de formar a la ciudadanía para la vida, para la propia situación vital en plenitud. La vida es para él el principio del que nace la metafísica, la única realidad radical de la que en todos los casos hay que partir, con la que hay que contar yque hay que resolver. Porque "en todo auténtico «entender», «razonar», etc., se produce un contacto inmediato entre el «yo» espiritual y lo entendido" (Ortega, 2005e, p. 575). Para el pensador se puede afirmar que "sólo podemos decir que hemos encontrado una verdad cuando hemos hallado un pensamiento que satisface una necesidad sentida por nosotros" (Escámez Sánchez, 1999, p. 9). El modo en que opera, consiste en formar a los alumnos para que tengan la capacidad de discernir en cada momento sobre las opciones más profundas a realizar. 
Hablamos así de una forma particular de sabiduría en donde la persona se abre interior y prudentemente, de manera eficaz, a la realidad de la existencia y el misterio de la libertad de los otros ciudadanos.

El logro formativo alcanzado, que resume lo afirmado hasta aquí, en relación a tal educación cívica, es siempre incierto, inexacto y cambiante, sin dejar de tener gran importancia en la vida de cada de persona y para la sociedad en su conjunto. Se trata, como ya señaló Aristóteles en su Política, de promover la prudencia social, o lo que es igual, la sabiduría en el trato personal, que sirva para pronosticar y promover posibles comportamientos en asuntos de importancia. Aunque como decimos, tal comportamiento no anule la incertidumbre, ya que esa formación personal no actúa como las matemáticas o la física y su uso en la naturaleza: "el saber científico es cerrado y firme mientras que nuestro saber vital sobre los demás y sobre nosotros mismos es un saber abierto, nunca firme y de un dintorno flotante" (Ortega, 2010a, p. 245).

\section{Educar en democracia: libertad, autoridad, tolerancia y elegancia}

Es del todo claro que el planteamiento orteguiano gira en torno a la idea del poder social de la libertad interior de los ciudadanos, ya que: "no hay una sola libertad determinada de que el hombre no pueda prescindir y, sin embargo, continuar sintiéndose libre" (Ortega, 2006a, p. 105).

No podemos hablar en Ortega de libertad ciudadana sin hacer mención al valor que tiene la autoridad política junto a ella. La relación entre libertad y ciudadanía pasa sin duda por un planteamiento de índole moral que incide en la participación social de los ciudadanos en la gestión responsable de la cosa pública. Para Ortega el uso del poder político en las sociedades no podrá ser nunca instrumental o amoral, tal y como lo entendió Maquiavelo, al servicio que el poder quiera hacer de la ética. Yendo más allá de esa deformación, en este autor no existe la idea de que un ciudadano o grupo social o político se apropie completamente del poder, de modo que éste comience a formar parte de su vida de manera estable y definitiva. Tal forma de pensar irá indisociablemente unida a la desestructuración social y, de un modo u otro, provocará a la postre el uso instrumental e interesado de la fuerza en beneficio de intereses particulares, dando pie a dictaduras de todo signo político, engendrando en la mente de los ciudadanos el temor a las represalias de los poderes unida a la mediocridad personal, produciendo, al menos, sociedades asustadizas y escasamente creativas. No se puede olvidar que todo poder, toda estructuración jerárquica de una organización humana, desde un punto de vista orteguiano está inscrito en una narrativa vital coherente y por ello su función versará sobre la participación personal y ordenación de las perspectivas de todos hacia el bien común, ya que "un hombre no es eficaz por sus cualidades individuales, sino por la energía social que la masa ha depositado en él" (Ortega, 1981, p. 72).

Podemos por concluir que la filosofía perspectivista de Ortega está unida también a una visión de la tolerancia y formación para la misma válida para cualquier sociedad. Es importante formar a los educandos desde la infancia para que no caigan en el 
despotismo del uso del poder o la fuerza a la que tienen acceso, siendo por el contrario capaces de ponerse en la mente ajena y desarrollar capacidad de comprensión y servicio a las otras personas. Consiste en enseñar, con prudencia, el misterio de la vida de cada hombre. Esto no es sólo un ideal abstracto, sino también una meta que cada educador ha de considerar, ya que "es tan congénito a los hombres ser unos para otros más o menos arcano, misterio y, ya por ello sólo, más o menos peligro, que esta deficiencia y minúsculo drama constante en que se ha convertido que da a nuestra convivencia sabor y aliciente, hasta el punto de que si de pronto nos trasluciésemos todos e interpretásemos sufriríamos una enorme desilusión y no sabríamos qué hacer con una vida etérea que no choca constantemente con el prójimo" (Ortega, 2010a, p. 286).

Preparar a cada persona para que desarrolle una gran sensibilidad en su vida cotidiana y conozca y respete profundamente a los demás, porque "el mundo está lleno de charlatanes, de vanidosos, de embaucadores, de dementes" (Ortega, 2008i, p. 289). Que cada hombre aprenda y se esfuerce en situarse en el ángulo de visión de los otros, para conocerlos y captar la "sensibilidad vital" de cada momento y cada época (Ortega, 2005c, p. 562). Esto el pensador lo asociará con lo que denomina como habilidad de "distinguir entre personas" ya que "la vida de una sociedad y más aún de un pueblo depende de que sus individuos sepan distinguir entre los hombres y no confundan jamás al tonto con el inteligente, al bueno con el malo" (Ortega, 2005b, p. 233). Aquí es donde radica para el pensador el realismo político de un ciudadano bien formado, el cual "consiste, pues, en hacerse cargo de que la máxima realidad, la que lleva, soporta y da un sentido a todos los hechos públicos - sea una postura internacional, sea un motín callejero, sea la hostilidad contra un impuesto- es el estado espiritual de las gentes que integran la sociedad" (Ortega, 2008c, p. 883).

Esta idea orteguiana, como se decía antes, choca frontalmente con cualquier intento de afirmación dogmática del propio punto de vista frente al de otro hombre y se refleja en la visión filosófica de El Quijote que posee Ortega. El Caballero de la Triste Figura es para Ortega pura perspectiva y unidad e integración de puntos de vista (2008, p. 789), para entender la realidad como una objetividad compartida que navega entre el drama de la propia vida y la acogida y el entendimiento de los demás (Carpintero, 2006, pp. 233-247).

Las sociedades democráticas para Ortega no se articulan sin la necesidad del debate franco, de la discusión abierta y sin tapujos como las que se dan entre Quijote y Sancho. Gracias a ella se consiguen pulir las ideas de los que participan en la dinámica compartida y apasionada de la aclaración de la libertad y responsabilidad de cada persona y su plasmación en la sociedad por sus miembros, la cual garantizará "una participación real, y no ficticia, de todos los ciudadanos en la esfera pública" (Bárcena, 1991, p. 65). Por eso la educación para la tolerancia consiste también en no olvidarse de la formación de los educandos en el debate y la sana polémica. Aspecto muy importante en la realidad española de nuestros días, donde tristemente pocos saben discutir exponiendo valiente, certera y rigurosamente el propio punto de vista, sin herir ni faltar el respeto a los demás. El filósofo explica de forma bella la tolerancia como la 
"lucha con un enemigo a quien se comprende (...) la actitud propia de toda alma robusta (Ortega, 2008b, p. 750).

Para finalizar este epígrafe, la formación para la libertad en la democracia en Ortega está unida a un aspecto, tan sencillo como olvidado, que consiste en educar a los miembros de la sociedad para que sean interiormente elegantes. Una virtud, en la que en Ortega se relaciona su liberalismo con su propio estilo señero de gentleman (Pallottini, 1995, p. 139) y que es tan necesaria para la buena convivencia.

La enseñanza de la elegancia en Ortega no sólo será externa, por ejemplo, aprender a vestir o decorar la propia casa, sino también interna tratando a los demás ciudadanos de una determinada manera, con la dignidad que merecen. Consiste en que las personas aprendan a vivir y a elegir de manera sensata entre las cosas que les rodean, de ahí proviene la palabra elegancia, eligere. Determinarse por aquellas realidades que componen el sentido del propio mundo, estando en cálida armonía con las cosas y frente al resto de ciudadanos: "debe penetrar, informar la vida íntegra del hombre desde el gesto y el modo de andar, pasando por el modo de vestirse, siguiendo en el modo de usar el lenguaje, de llevar una conversación, de hablar en público, para llegar hasta lo más mínimo de las acciones morales e intelectuales" (Ortega, 2010b, pp. 4849).

Esta idea pedagógica da profundidad a la sociedad y engarza con la visión orteguiana de formación de la inteligencia al servicio del bien común, ya que: "el capricho es hacer cualquiera cosa entre las muchas que se pueden hacer. A él se opone el capricho y hábito de elegir, entre las muchas cosas que se pueden hacer, precisamente aquella que reclama ser hecha. A ese acto y hábito del recto elegir llamaban los latinos primero eligentia y luego elegantia. Es, tal vez, de este vocablo del que viene nuestra palabra int-eligencia" (Ortega, 2009, p. 583).

\section{Formar la intimidad de cada ciudadano}

Uno de las grandes amenazas que según Ortega acechan a todas las democracias y que denuncia en su libro La Rebelión de las Masas (1930) es la llamada despersonalización del hombre. Es probable que si hoy viviera este intelectual no se extrañaría al ver cómo, con la extensión de las redes sociales y algunos medios de comunicación de nuestros días, tal despersonalización ha avanzado exponencialmente teniendo una nefasta influencia en la formación de los ciudadanos de las democracias modernas. Ortega denunciaba entonces la intención de algunos movimientos sistemáticamente organizados para conseguir alcanzar tal meta socialmente disruptiva: "los demagogos, empresarios de la alteración, que ya han hecho morir a varias civilizaciones, hostigan a los hombres para que no reflexionen, procuran mantenerlos hacinados en muchedumbres para que no puedan reconstruir su persona donde únicamente se reconstruye, que es en la soledad. Denigran el servicio de la verdad y nos proponen en su lugar mitos" (Ortega, 2010a, p. 154).

En pleno siglo XXI quizá podríamos extender esta denuncia a los impulsores del consumismo o de la cultura del ocio basada en el ruido y el estrépito. En esta línea, 
particularmente Ortega indagó en lo pernicioso del activismo como modo de manipulación sobre el Yo personal. En resumidas cuentas nuestro filósofo deplora al "hombre exterior" que vive de cara al mundo y, por ignorancia y atolondramiento, sólo se preocupa de acatar los códigos de conducta, los tópicos y lugares comunes. Esta actitud y modo de vida trasforma al ciudadano en inauténtico, y, tal vez de modo inconsciente, le llevará a renunciar a su libertad y por consiguiente a guiarse sólo por el entorno social (Ortega, 2008e).

Cuando Ortega habla de la intimidad del hombre, del Yo, lo concibe no como resultado de una auto-conceptualización, tal y como lo entiende frecuentemente la psicología moderna, sino como el centro del que proceden la actividad y los actos más genuinos de la persona (Hierro Sánchez-Pescador, 2005, p. 113). Por tanto es un refugio personalísimo hacia al que el ser humano se puede retirar, porque supone ir hacia sí mismo: "el tener dónde meterse, donde estar, cuando se ha salido virtualmente del mundo" (Ortega, 2010a, p. 144). De este modo en Ortega la vida interior, la vida del espíritu, se convierte en el centro de gravedad en el que reposa la vida personal del ciudadano, la cual le hará brotar de forma auténtica desde sí mismo a las cosas (Álvarez González, 2010, p. 28). Un espacio de claridad y sentido ante el tráfago del mundo; allí donde se puede llegar a contemplar la relevancia y calado de los problemas que ocupan al hombre. Tal es el papel que tiene la educación en una sociedad, formar la sensibilidad para ponderar los problemas que nos ocupan. Una vez que se produce esto en el interior de la persona "lo demás, esto es, las soluciones se nos darán por añadidura" (Ortega, 2007a, p. 570).

Así, en este autor, cuando el individuo pierde su centro interior, su rica soledad, y se halla fuera de sí, entonces se convierte en un ser excéntrico y desquiciado, presa fácil de la manipulación o el engaño. Es cuando los comportamientos personales y sociales dejan de tener armonía y sentido en la propia vida. De manera que formar la intimidad consiste en facilitar y promover en los educandos esos momentos de tranquila soledad y reflexión. Aunque no hay que olvidar por eso el deseo inherente a todo ciudadano de "desoledarizarnos asomándonos al otro ser humano deseando darle nuestra vida y recibir la suya" (Ortega, 2010a, p. 195).

En relación a ambas cosas la educación del Yo de los ciudadanos tiene un valor incalculable, ya que el problema no es educar al hombre exterior, al que simplemente convive forzosamente con los demás, sino al hombre interior, al hombre que piensa, siente y quiere desde el inicio de su vida junto y con los otros (Morón Arroyo, 2005, p. 687). De ahí que el desarrollo de la intimidad sea una meta fundamental para la educación democrática. Un buen ciudadano, educado en términos orteguianos, experimenta íntima y profundamente el sentido de su propia existencia en relación a sí mismo y a los demás de un modo más libre y verdadero que el resto de la gente. Dado que para Ortega "cada nuevo concepto es un nuevo órgano que se abre en nosotros sobre una porción del mundo, tácita antes invisible. El que os da una idea os aumenta la vida y dilata la realidad en torno vuestro" (2008b, p. 788). Por ello se puede afirmar que es importante en Ortega el hecho que "las acciones educativas son acciones intencionales, reflexivas, tras la consecución de una meta: cooperar técnicamente en la 
maximización del potencial vital más profundo de los niños" (Escámez Sánchez, 1999, p. 815).

De todo lo expuesto aquí se puede deducir la gran importancia que tiene la figura del formador y su labor personalizada, entendida esta no sólo como un trato cercano entre el educador y el educando, sino como una ayuda directa en la forja de la intimidad que actúa en la soledad del alumno como "herrero trascendente" (Ortega, 1985, p. 224). Tal formación se produce por lo que Ortega denomina como una pedagogía en la que más que inculcar el profesor "contamina" con sus conocimientos y su amor por el saber a sus alumnos (Ortega, 2007d). Por eso no sólo trabaja en la preparación intelectual o volitiva de los educandos sino como experto en humanidad, capacitando internamente. Si miedos ni complejos, el educador debe penetrar delicada y prudentemente en la interioridad de sus alumnos y, contando siempre con su libertad, moldear la intimidad con sus palabras y acciones. Así lo afirma en la siguiente cita: "El profesor que lo sea en verdad no está del lado de acá de su cátedra: está ahí, en los oyentes, no diré que literalmente en todos, pero sí en la mayor parte y con cada uno en su individualidad. Y el caso es que los oyentes mismos lo advierten como se demuestra con que el oír todo lo anterior se sentirían un poco azorados temiendo que el pensamiento del profesor alargando como una mano espectral penetre en su intimidad y saque de ella un secreto que creían tener en ella suficientemente oculto" (Ortega, 2006b, p. 314).

\section{Conclusión}

Ortega y Gasset no fue un pedagogo ni un filósofo de la educación al uso, aunque su vida como profesor universitario y conferenciante y también algunas de sus obras están llenas de reflexiones relacionadas con la formación de ciudadanos de plena actualidad en nuestros días.

Para este autor la filosofía raciovitalista consiste en esa relación que siempre existe entre el conocimiento de la realidad y la vida humana. Lo cual supone, como en cierto modo también realiza el llamado meta-análisis educativo, resaltar la importancia de la perspectiva personal, del propio punto de vista, junto a la circunstancia de cada uno en relación al entendimiento de las cosas y la aportación al bien común. De aquí se deriva el sentido de la tolerancia basada en la atención a la variedad con la que cada ciudadano accede a su propia realidad, para construir de este modo de forma exitosa la convivencia y la vida en común de las personas.

Entiende Ortega el liberalismo y la necesidad de la plasmación de éste en partidos políticos, como una proyección social de sus ideas antropológicas y éticas y como un elemento clave a difundir en la educación de las sociedades modernas. Ser liberal es aquí un modo de entender la relación entre el mundo interior de cada ciudadano y la forma en que éste se plasma en vivencias libremente compartidas con los otros, de forma similar a cómo hoy en día se propone en el aprendizaje cooperativo.

Considera Ortega por ello que la fuerza de la libertad es expansiva, articuladora de toda forma de convivencia cívica y creadora de bienes. Por medio de la libertad, unida 
a la responsabilidad, al esfuerzo, a la alta cultura, la educación y la virtud, irán apareciendo en la sociedad individuos de gran valía. Una excelsa minoría, que no supone un condición genética (Zamora, 2005, p. 48), que podrá dirigir con sabiduría al resto hacia el bien común.

Por eso, en este autor, para que la formación en la libertad se habrá paso, debe ser equilibrada, completa y caminar junto con la educación en la responsabilidad, en la consideración y en la promoción de la elegancia interior y exterior de los educandos, como modo habitual de trato entre ellos.

Para el filósofo todo esto no se consigue, tal y como se busca en la actualidad, por el desarrollo de competencias para resolver problemas prácticos de convivencia, sino por medio de la formación de la intimidad, para que la conciencia de cada uno, la llamada "voz insobornable", se refleje en la vida social. Cuando ocurre así la vida de los educandos se trasforma en un proyecto auténtico de valor incalculable para todos.

Frente al exagerado respeto a la interioridad personal con el que actúa la educación de nuestros días, cada educador aparece como un guía al viaje a la intimidad de cada hombre, el cual no conlleva en sí desprecio, olvido o alejamiento de la sociedad. Es así, ya que, según Ortega, si uno se examina descubre que gran parte de las propias "opiniones y sentimientos no son suyos, no han brotado espontáneamente de su propio fondo personal, sino que son bien mostrenco, caído del contorno social dentro de su cuenca íntima, como cae sobre el transeúnte el polvo del camino" (1969, p. 96).

\section{Referencias bibliográficas}

ÁLVAREZ GONZÁLEZ, E. (2010) La vida del Yo: el problema del sujeto en Ortega. Signos Filosóficos, vol. XXII, 24, julio-diciembre, pp. 25-47.

BÁRCENA, F. (1983) La dimensión educativa del problema de la verdad en el pensamiento de José Ortega y Gasset. Revista Española de Pedagogía, 160, abriljunio, pp. 311-324.

BÁRCENA, F. (1991) Filosofía pública y educación. La reconstrucción de la educación cívica. Teoría de la Educación, vol. 3, pp. 59-73.

CARPINTERO, H. (2006) Ortega y El "Quijote". Los primeros apuntes. Anales del Seminario de Historia de la Filosofía, vol. 23, pp. 233-247.

CEREZO GALÁN, P. (2005) Ortega y la regeneración del liberalismo: tres navegaciones y un naufragio, en: Meditaciones sobre Ortega y Gasset, Madrid: Tébar.

ESCÁMEZ SÁNCHEZ, J. (1999) José Ortega y Gasset (1883-1955). Perspectivas: revista trimestral de educación comparada, vol. XXIII, 3-4, pp. 808-821.

HIERRO SÁNCHEZ-PESCADOR, J. (2005) La idea del Yo en Ortega y Gasset, en: Meditaciones sobre Ortega y Gasset, Madrid: Tébar. 
JOVER, G., THOILLIEZ, B. (2011) A propósito de Joao Boavida y el Debate sobre las finalidades de la Educación Superior: los casos de John Dewey y José Ortega y Gasset. Revista Portuguesa de Pedagogía, Extra-série, pp. 253-267.

MACINTYRE, A. (1984) Is Patriotism a Virtue? en: Lindley Lecture, Kansas: University of Kansas Press.

MORÓN ARROYO, C. (2005) La idea de lo social en Ortega, en: Meditaciones sobre Ortega y Gasset, Madrid: Tébar.

ORTEGA Y GASSET, J. (1981) España invertebrada. Madrid: Alianza.

ORTEGA Y GASSET, J. (1985) La socialización del hombre, en: El Espectador, Tomos VII y VIII, pp. 223-226. Madrid: Espasa.

ORTEGA Y GASSET, J. (2005) La Rebelión de las Masas, O. C, vol. IV (1926/1931), pp. 349-506. Madrid: Taurus.

ORTEGA Y GASSET, J. (2005a) La Pedagogía Social como programa político, O. C, vol. II (1916), p. 86. Madrid: Taurus.

ORTEGA Y GASSET, J. (2005b) Para los niños españoles, O. C, vol. IV (1926/1931), pp. 233-237. Madrid: Taurus.

ORTEGA Y GASSET, J. (2005c) El tema de nuestro tiempo, O. C, vol. III (1917/1925), pp. 559-611. Madrid: Taurus.

ORTEGA Y GASSET, J. (2005d) Mirabeau o el político, O. C, vol. IV (1926/1931), pp. 195-219. Madrid: Taurus.

ORTEGA Y GASSET, J. (2005e) Vitalidad, alma y espíritu, O. C, vol. II (1916), pp. 566-585. Madrid: Taurus.

ORTEGA Y GASSET, J. (2006a) Historia como sistema y del imperio romano, O. C, vol. VI, (1941/1955), pp. 45-76. Madrid: Taurus.

ORTEGA Y GASSET, J. (2006b) Los que estudian filosofía como profesión y los que buscan una claridad sobre la vida, O. C, vol. V (1932/1940), pp. 312-315. Madrid: Taurus.

ORTEGA Y GASSET, J. (2006c) Ideas y creencias, O. C, vol. V (1932/1940), pp. 657-747. Madrid: Taurus.

ORTEGA Y GASSET, J. (2006d) Prólogo de aventuras del Capitán Alonso de Contreras, O. C, vol. VI, (1941/1955), pp. 334-353. Madrid: Taurus.

ORTEGA Y GASSET, J. (2007) Elogio de las virtudes de la mocedad, O. C, vol. VII (1902-1925), pp. 839-842. Madrid: Taurus.

ORTEGA Y GASSET, J. (2007a) Introducción a los problemas actuales de la filosofía, O. C, vol. VII (1902-1925), pp. 557-655. Madrid: Taurus.

ORTEGA Y GASSET, J. (2007b) Misión de la universidad. Madrid: Alianza. 
ORTEGA Y GASSET, J. (2007c) Unas Lecciones de Metafísica. Madrid: Alianza Editorial.

ORTEGA Y GASSET, J. (2007d) La pedagogía de la contaminación, O. C, vol. VII, (1902-1925), pp. 685-692. Madrid: Taurus.

ORTEGA Y GASSET, J. (2007e) Liga de educación política española, O. C, vol. VII, (1902-1925), pp. 328-332. Madrid: Taurus.

ORTEGA Y GASSET, J. (2008) Meditaciones del Quijote, O. C, vol. I (1902/1915), pp. 747-823. Madrid: Taurus.

ORTEGA Y GASSET, J. (2008a) La conservación de la cultura, O. C, vol. I (1902/1915), pp. 147-155. Madrid: Taurus.

ORTEGA Y GASSET, J. (2008b) Prospecto de la "liga de educación política española", O. C, vol. I (1902/1915), pp. 738-744. Madrid: Taurus.

ORTEGA Y GASSET, J. (2008c) Ideas políticas, O. C, vol. I (1902/1915), pp. 882889. Madrid: Taurus.

ORTEGA Y GASSET, J. (2008d) La ciencia romántica, O. C, vol. I (1902/1915), pp. 87-92. Madrid: Taurus.

ORTEGA Y GASSET, J. (2008e) Principios de metafísica según la razón vital curso 1932-1933, O. C, vol. VIII (1926/1932), pp. 555-661. Madrid: Taurus.

ORTEGA Y GASSET, J. (2008f) Vieja y nueva política, O. C, vol. I (1902/1915), pp. 710-744. Madrid: Taurus.

ORTEGA Y GASSET, J. (2008g) ¿Qué es la ciencia, qué la filosofía?, O. C, vol. VIII (1926/1932), pp. 117-159. Madrid: Taurus.

ORTEGA Y GASSET, J. (2008h) Meditación de nuestro tiempo, O. C, vol. VIII (1926/1932), pp. 31-102. Madrid: Taurus.

ORTEGA Y GASSET, J. (2008i) ¿Qué es filosofía?, O. C, vol. VIII (1926/1932), pp. 235-359. Madrid: Taurus.

ORTEGA Y GASSET, J. (2009) Epílogo de la filosofía, O. C, vol. IX (1933/1948), pp. 583-610. Madrid: Taurus.

ORTEGA Y GASSET, J. (2010a) El hombre y la gente (1949-1950), O. C, vol. X (1949/1955), pp. 139-323. Madrid: Taurus.

ORTEGA Y GASSET, J. (2010b) Apuntes para una escuela de humanidades en Estados Unidos, O. C, vol. X (1949/1955), pp. 44-52. Madrid: Taurus.

ORTEGA Y GASSET, J. (2012) El collar de la paloma (prólogo a la obra de Ibn Haszm, trad: Emilio García Gómez). Madrid: Alianza.

PALLOTTINI, P. (1995) Liberalismo y democracia en Ortega y Gasset. Revista de

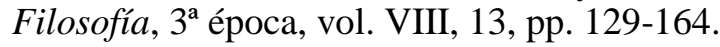


RUÍZ HERNÁNDEZ, J. (2009) La idea de filosofía en Ortega y Gasset. Memoria para optar al grado de doctor. Madrid: Servicio de publicaciones de la Universidad Complutense.

ZAMORA BONILLA, J. (2005) Semblanza histórica, en: Meditaciones sobre Ortegay Gasset, Madrid: Tébar.

\section{Correspondencia con el autor}

Miguel RUMAYOR

Paseo de la Ermita 10, 1-b

28023, Madrid, España.

e-mail: mrumayor@up.edu.mx 